Forschende

Komplementärmedizin und

Klassische Naturheilkunde
Letters to the Editors - Briefe an die Herausgeber

Forsch Komplementärmed Klass Naturheilkd 2005;12:292

DOI 10.1159/000088635

\section{On: Economy Chased Medicine: Health under the Provision of Economy - Chance or Threat for CAM?}

In his editorial, Prof. Walach seems to argue that the main determinant of reimbursability of medical interventions will in future be their cost [1]. Efficacy, he believes, will play a subordinate role and safety is not even mentioned. Prof. Walach believes that, because of economic reasons, complementary medicine was recently put on the 'negative list' in Switzerland. He continues stating that 'most of what is effective works by stimulating the self-healing properties in one way or another so that the organism finds its own way back to health', and feels that, in future, 'the question will be: which placebo is cheaper, longer lasting, less burdened with adverse effects and more popular?' [my translation].

I think Prof. Walach's views are profoundly misguided. If cost were the overriding determinant, why did the Swiss authorities not ban bone marrow transplants, for example? One such intervention probably costs a similar amount of money as all the homoeopathic remedies used in Switzerland during many months! Clearly, efficacy must remain a decisive factor even if, in this 'brave new world', the accountants take over - they too require effective treatments every now and then!

Walach furthermore displays an amazing level of ignorance when suggesting that most medical treatments are essentially placebos (see quote above). All therapies can generate powerful placebo effects (remember: we don't need placebos to induce placebo effects!) but most (e.g. antibiotics, beta-blockers, corticosteroids, insulin, surgery, taxol and many more) have even more powerful specific therapeutic effects in addition. To imply otherwise is, in my view, not worthy of a respected medical journal.

I predict that the future will look dramatically different from Walach's vision (or should I say nightmare?). To survive in the long term, any treatment will need to be firmly associated with a positive risk-benefit balance. Only if several interventions exist for the same indication which all meet this essential criterion, cost will be a truly decisive factor. Thus the ultimate question will not be, 'which placebo is cheaper etc.?' but increasingly, 'which therapy is more than a placebo?'.

E. Ernst, Exeter

\section{References}

1 Walach H: Economy Chased Medicine: Ökonomisierung der Gesundheit Chance oder Bedrohung für die Komplementärmedizin? Forsch Komplementärmed Klass Naturheilkd 2005;12:188-189.

\section{Author's Reply}

Prof. Ernst has reiterated an important fact that is both well known, and loudly and proudly stated from many quarters. Contrary to him I believe it is not the task of scientists, scholars, or philosophers to state the obvious. That is the domain of politics. The field of science is to question the obvious, to ask about the backstage of appearances and to find out about what is not obvious. That is what I have tried to contribute to, and I have done this, as always, in a deliberately provocative way, which has done what it was meant to do, as Prof. Ernst's reply shows. Future is an open process, and every prediction is an attempt to influence it. In that sense, my (negative) prediction was an attempt to influence it towards a more positive direction. We will see who is better at foreseeing the future in a while. Regarding the presumably efficacious methods of conventional medicine, which by and large certainly do have some specific effects, no doubt, I would advise Prof. Ernst, and indeed other readers, to have a quick glance (or a slower one, if he can spare his time) at our latest publication on placebo effects and treatment effects in conventional trials [1]. It shows a correlation of $\mathrm{r}=0.78$ between treatment and placebo effects in conventional, pharmaceutical trials. A very benevolent interpretation of that finding is that the specific effect of conventional studies is, by and large, not a rather convincing one. For if both treatments were equally effective or ineffective, the correlation would be 1 . In terms of reliability, a reliability coefficient of $r=0.78$ would be considered close to unity and sufficiently large. In terms of efficacy, where unity means zero specific efficacy, what would the result be? I leave it to Prof. Ernst and the reader to do the maths.

H. Walach, Northampton

\section{References}

1 Walach H, Sadaghiani C, Dehm C, Bierman DJ: The therapeutic effect of clinica trials: Understanding placebo response rates in clinical trials - a secondary analysis. BMC Med Res Methodol 2005;5:26. www.biomedcentral.com/content/pdf/1471 2288-5-26.pdf. 